\title{
CAMPOS RELACIONALES DE LAS EXPERIENCIAS DE CONOCIMIENTO RITUAL ENTRE LOS HUICHOLES DE MÉXICO
}

\author{
RELATIONAL FIELDS OF THE EXPERIENCES OF RITUAL \\ KNOWLEDGE AMONG THE HUICHOL OF MEXICO
}

\author{
Ángel Aedo y Paulina Faba ${ }^{2}$
}

\begin{abstract}
En las localidades huicholas de Jalisco y Nayarit el acto de conocer se manifiesta como una experiencia transformacional, en donde concepciones de la verdad y valores circulan a través de las interacciones entre agentes humanos y no humanos. Mediante el análisis de nociones críticas, experiencias rituales y ensamblajes de cosas, este artículo examina las formas huicholas de conocimiento a través de cuatro fenómenos: la anticipación de la experiencia, la indeterminación de lo conocido, la presencia de índices de agencia y devenir en imágenes rituales, y el desplazamiento de subjetividades. Sobre la base de una reflexión emanada de la etnografía, el artículo finaliza subrayando la necesidad de examinar las formas en que se entrelazan acciones, discursos y elementos visuales para comprender cómo se forjan y operan "campos relacionales" dentro de los cuales tienen lugar experiencias de conocimiento ritual.

Palabras claves: conocimiento, experiencia ritual, indeterminación, campos relacionales, huicholes.
\end{abstract}

Among the Huichol of western Mexico, the act of knowing is considered a transformational experience where conceptions of truth and values circulate in interactions between human and non-human agents. Through the analysis of critical notions, ritual experiences and assemblages of things, this article examines Huichol forms of knowledge in four phenomena: the anticipation of experience, the indeterminacy of the known, the presence of indexes of agency and becoming in ritual images, and the shifting of subjectivities. On the basis of a reflection emanating from ethnography, the article concludes by stressing the need to examine the ways in which actions, discourses and visual elements are intertwined, in order to understand how "relational fields" are formed and operate as experiences of ritual knowledge.

Key words: Knowledge, ritual experience, indeterminacy, relational fields, Huichol Indians.

¿Qué significa la acción de conocer? ¿Cómo cosas y paisajes se entrelazan orientando formas particulares de conocimiento? Para los huicholes (wixaritari) del Occidente de México, preguntas como estas carecerían de sentido si no estuvieran enmarcadas por consideraciones prácticas que toman en cuenta las identidades e intenciones de los actores involucrados. El conocimiento depende -en contextos huicholes de interacción- de aquello que es vivido (küpuri), visto (nierika) y sentido/ pensado (iyary). Es precisamente el mundo vivido en su inmanencia, el que, argüimos, constituye la condición de posibilidad del acto de conocer.

El objetivo principal de este trabajo es, al mismo tiempo, etnográfico y teórico. Buscamos profundizar en el análisis de ciertos campos relacionales que dan sentido a la acción de conocer entre los huicholes, y arrojar luz sobre asuntos teóricos de agencia e intencionalidad dentro de procesos metapragmáticos (Silverstein 1993; Urban 2001) de creación de conocimiento. Durante 16 meses de trabajo de campo (entre 1998 y 2003), en cuatro localidades huicholas de Jalisco y Nayarit (Tateikita, Tateikie, Kwaxumayeme y Kwaxüparietu), fuimos dándonos cuenta de la importancia de los entrelazamientos entre cosas e imágenes en la producción de experiencias subjetivas y colectivas de conocimiento ${ }^{1}$. En este proceso, notamos que los actos de conocer, pensar y reflexionar, como argumentó Dewey, no son facultades, sino más bien "denotan indagaciones o resultados de indagaciones, las cuales ocupan un lugar intermedio y mediador en el desarrollo de una experiencia" (Dewey 1916:1). Mediante esta perspectiva, buscamos distanciarnos de visiones exotizantes de la diferencia cultural con el fin de situar el estudio del conocimiento huichol dentro

\footnotetext{
1 Programa de Antropología, ISUC. Pontificia Universidad Católica de Chile. Av. Vicuña Mackenna 4860, Macul, Santiago, Chile.jaedog@uc.cl

2 Departamento de Antropología, Facultad de Ciencias Sociales, Universidad Alberto Hurtado. Almirante Barroso 10, Santiago, Chile.pfaba@uahurtado.cl
} 
del problema más amplio concerniente a la base pragmática del conocimiento humano. Naturalmente, el hecho de reconocer los errores cometidos en la construcción antropológica de "fetiches culturales" (Morris 2000; Pietz 1985; Taussig 1993) no excluye la emergencia de "mundos radicales" que perduran a la sombra del capital global (Povinelli 2001), ni explica las formas singulares en las que los grupos humanos realizan actos universales, que están mediados culturalmente, como saber o dar sentido a algo.

Partiendo de la idea de que el conocimiento es algo que afecta a las personas brindándoles "materiales para la reflexión y premisas para la acción" (Barth 2002:1), argumentamos que el conocimiento, en lugar de ser concebido como un proceso consciente-racional, se asocia fundamentalmente entre los huicholes con procesos de conocimiento de sí mismo y con formas de relacionar, referir, interpretar y valorar trayectorias y experiencias. En este sentido, a través de revisión bibliográfica y el análisis del material etnográfico recopilado durante nuestro trabajo de campo, nos focalizamos en el estudio de dos contextos rituales huicholes relevantes para la comprensión de las concepciones y experiencias de conocimiento: las celebraciones anuales llamadas neixa y las peregrinaciones al desierto de Wirikuta, localizado en San Luis Potosí. En estos contextos, observamos la circulación de valores, las emociones y los criterios para la acción (Cavell 1999; Wittgenstein 1986).

En lugar de seguir los enfoques antropológicocognitivistas (Boyer 1994; D’ Andrade 1995; Højberg 2002; MacCauley y Lawson 2002; Sperber 1996; Whitehouse 2012), en este artículo analizamos el conocimiento en su dimensión experiencial. Nuestro propósito principal es explorar las diversas formas en que el acto del conocer implica entrelazamientos de intencionalidades con el potencial de comprometer seres, artefactos y fenómenos. Investigaciones antropológicas acerca de la religión y el pensamiento (Astuti y Bloch 2015; Berliner y Sarró 2008; Bloch 1998, 2012; Severi 2002, 2014) han demostrado que el aprendizaje y la transmisión ocurren a menudo en contextos de interacción social y no solo dependen de las capacidades cognitivas de la mente humana. En esta perspectiva, el estudio de las dimensiones performativas de los fenómenos sociales (Bauman 2012; Bauman y Briggs 1990; Goffman 1981; Zigon 2015) abre un camino para comprender cómo las experiencias de conocimiento pueden constituir campos relacionales de acciones (Bateson 1936; Houseman y Severi 1998).

Los objetos rituales y las imágenes también juegan un papel importante en los procesos de conocimiento huicholes. Los elementos visuales a menudo aparecen como índices de la agencia de entidades humanas y no humanas. A través de su entrelazamiento con acciones y objetos rituales, las imágenes, como aquellas grabadas en los discos de piedra teparite, despliegan un carácter performativo. Tal como constata Bredekamp (2015:215-285), muchos motivos figurativos y abstractos de expresiones visuales operan como "actos de imágenes intrínsecos". Lo que significa que las imágenes, de forma recurrente, tienden a desarrollar una presencia que las faculta para ser mucho más que materia inerte, teniendo el poder de mover a la gente a actuar.

El artículo se estructura en cuatro partes. En primer lugar, se argumenta que el conocimiento involucra la anticipación de la experiencia en el contexto de los rituales huicholes. En segundo lugar, se discute el papel fundamental desempeñado por la indeterminación de lo conocido y lo cognoscible a través del caso del peyote y el kieri. La tercera parte explora cómo los índices visuales rituales, tales como los discos de piedra teparite, operan como formas de agencia y devenir. Por último, se analiza la noción de nierika (el don de ver) y el desplazamiento de intencionalidades como entrelazamientos de conocimiento y experiencia.

\section{El Conocimiento como Experiencia Anticipatoria}

Perder el camino de vuelta a casa constituye un tema recurrente en los comentarios de los participantes del Tatei Neixa (la Danza de Nuestra Madre). Durante una de estas ceremonias, realizada en Tateikie el año 2002 al finalizar la temporada de lluvias, Eugenio, un chamán de Tateikita y sus dos ayudantes/aprendices cantaron y escenificaron un vívido viaje a la casa del peyote en Wirikuta. En esta ocasión, al igual que en los años anteriores, los niños de la comunidad, considerados como los primeros frutos, realizaron un viaje imaginario a Wirikuta, encaramados sobre las alas del águila incandescente Tatei Wierika Wimari.

Durante el Tatei Neixa a los participantes del ritual se les proporciona la oportunidad de compartir 
una fuerte experiencia anticipatoria, la cual tiene el potencial de crear nuevas formas de relación con el espíritu del peyote a través de la imaginación de su tierra natal y de los seres que allí habitan. Como Eugenio refirió mediante sus cantos y gestos, este viaje no está exento de peligros, ya que los niños corren siempre el riesgo de caerse en pleno vuelo ritual.

Deleuze refiere que un viaje real, por sí mismo, carece de la fuerza necesaria para reflejarse en la imaginación. Para este autor "el viaje imaginario no tiene la fuerza [...] para ser verificado en lo real. Es por ello que lo imaginario y lo real deben ser, más bien, como dos partes yuxtapuestas o superponibles en una sola trayectoria, dos caras que sin cesar se intercambian entre sí, un espejo móvil" (Deleuze 1997:62-63). El poder de la experiencia del Tatei Neixa reside en el desplazamiento de los niños desde las localidades huicholas a un lugar que se les presenta, paradójicamente, como un paisaje desconocido y familiar a la vez. Más temprano que tarde, los niños de la comunidad deben emprender una peregrinación física a dicho lugar sagrado. En este sentido, más que un viaje que es meramente representado, este ritual actúa como una imagen virtual que se funde con un lugar real: Wirikuta, la tierra del peyote.

El sentido de desorientación que impregna la experiencia de Tatei Neixa, se encuentra marcado por la búsqueda de reglas de acción, en el sentido de lo que Wittgenstein (1986) entiende por "criterios". En la vida cotidiana, los criterios a partir de los cuales "sintonizamos" nuestras acciones y expectativas con las de los otros son usualmente tácitos e indefinidos. Como observa Stanley Cavell (1999:34), apelamos a criterios cuando desconocemos nuestro camino de regreso a casa, cuando estamos perdidos en relación con nuestras palabras y con el mundo que ellas anticipan.

En tales situaciones, los rituales huicholes como el Tatei Neixa y el Hikuri Neixa, no solo tratan con representaciones religiosas; ellos también activan -en una arena ética y política- diferentes "formas de vida", tales como aquellas que encarnan el kieri (del cual hablaremos en la siguiente sección) y el peyote. De este modo, los pasos para ser guiado por el peyote se sustentan en criterios arraigados en el alto valor del autosacrificio, en la práctica de la reciprocidad, en la dignidad del ascetismo ritual y en la sabiduría y el prestigio de los ancianos/ antepasados.
Diversos estudios etnográficos (Furst 1972; Gutiérrez 2002; Lemaistre 2003; Myerhoff 1974; Neurath 2002; Schaefer 2005; Schaefer y Furst 1996) se han referido a la importancia del papel desempeñado por el peyote en la socialización de los huicholes. El peyote está en el centro de todo un ciclo ritual agrícola conocido como neixa, el cual se articula en torno a la ceremonia de la lluvia Hikuri Neixa (el ritual del peyote). El peyote juega también un rol fundamental en el ciclo ritual "católico" que es recreado por los huicholes, sobre todo cuando los peregrinos del peyote (hikuritamete) consumen este cactus sagrado el domingo de Pascua, día de la conmemoración de la resurrección de Cristo-Sol Tawewiekame. Debido a sus propiedades medicinales y alucinógenas, el peyote (Lophophora williamsii), desempeña un papel primordial en curaciones y prácticas rituales. Como Abundio y varios otros habitantes de Tateikie nos explicaron, esta entidad es también vista como manifestando sus propios pensamientos y voluntad. Bajo esta última dimensión, el peyote adquiere la forma de distintos númenes cuyos diferentes caracteres se expresan mediante nombres propios, como Paritsika (deidad del alba), Tamatsi Kauyumari "Nuestro Hermano Mayor el Venado" (héroe cultural que dio su vida para crear al peyote) y Parikuta Muyeka ("el que camina al amanecer") ${ }^{2}$. Las diferentes manifestaciones del peyote tienen en común el hecho de ser actores cruciales de los procesos de curación. En este sentido, puede decirse que el peyote no es simplemente un espíritu ayudante del chamán, ya que puede actuar como un chamán por sí mismo. Este fenómeno se manifiesta en dos planos diferentes de acción: en la lucha dirigida por el espíritu del peyote en contra de los agentes causantes de enfermedad en un plano paralelo de la realidad, y a través de la encarnación del peyote por un cantador ritual (mara'akame), quien permite (en su unión con el peyote) engendrar un nuevo y excepcional ser chamánico que sintetiza varias presencias, dando lugar a lo que Severi (2014), en su propuesta para una antropología del pensamiento, describe como "seres complejos".

En este campo de experiencias colectivas, los entrelazamientos con el peyote contribuyen a dar forma a subjetividades morales (Fassin 2012; Faubion 2011) mediante una ética particular de cuidado de sí (Foucault 1988, 1990, 2012), la cual, entre otras prácticas, se despliega por la observancia rigurosa de reglas de abstinencia, de la vigilia ritual 
forzada (dormir en las ceremonias neixa y durante la peregrinación a Wirikuta es visto como una falta grave o incluso un tipo de enfermedad), del esfuerzo físico prolongado y de la adopción de una estricta dieta sin sal, consistente principalmente en tortillas de maíz y frijoles.

El venado posee una compleja simbiosis con la ontología del peyote, ya que ambos son "formas de figuración" (Descola 2010) del ser proteico Tamatsi Kauyumari. Los huicholes de las localidades Tateikie y Tateikita en Jalisco, y los habitantes de Kwaxumayeme y Kwarüpaxietu en Nayarit, interactúan con el peyote en etapas críticas de su desarrollo biológico y moral. De esta forma, las fuerzas de transformación del peyote ofrecen instancias fundamentales para que un individuo pueda devenir una persona realizada (tewi). La cacería ritual del venado (maxa) y la primera peregrinación a la meseta desértica de Wirikuta ${ }^{3}$ son experiencias que constituyen hitos significativos de las formas de conocimiento en la vida de los huicholes.

\section{La Indeterminación de lo Conocido}

En las trayectorias Huicholas de conocimiento ritual, lo que se conoce aparece generalmente como indeterminado y ambivalente. Dos marcos semánticos y prácticos configurados por las nociones de kieri y peyote, ofrecen una vía para investigar el rol crucial de la indeterminación de lo conocido en las experiencias de conocimiento. A través del peyote y del kieri opera una suerte de "gobierno de las cosas" (Foucault 2007; Lemke 2014), que permite la interrelación de humanos y no humanos, así como la indistinción de lo físico y lo moral, de lo natural y lo artificial. En términos de Peirce, estas fuerzas desencadenan semiosis inacabables (Peirce 1931-1958). Sus ensamblajes cambiantes y sus intencionalidades fluctuantes se cristalizan en índices que aparecen en situaciones con el potencial de crear experiencias reales en la vida social, intelectual y moral de los huicholes. Ambas entidades tienen la capacidad de ensamblar elementos y fenómenos heterogéneos que manifiestan una multidimensionalidad constitutiva.

Mientras que el cactus hikuri, popularmente conocido como peyote, crece en el desierto sagrado de Wirikuta, en el extremo oriental del territorio huichol, el arbusto kieri (Solandra brevicalyx) habita en acantilados y tierras bajas en el oeste, más allá del cual se encuentra un paisaje subtropical húmedo habitado por la población mestiza mexicana (Aedo 2008; Knab 1977). Estas zonas son tan distantes la una de la otra que ellas encarnan las antípodas de la geografía ritual huichola. A pesar de sus diferencias morfológicas y ecológicas, kieri y peyote comparten la característica de contener alcaloides que pueden producir efectos psicotrópicos en los seres humanos. Las fuerzas de transformación encarnadas en el peyote y el kieri tienen la habilidad de vivir en una variedad casi infinita de cuerpos: ya sea orgánicos o inorgánicos, vegetales o animales, humanos o no humanos, meteorológicos o astronómicos (Aedo 2011).

Los fenómenos asociados al kieri, constituyen para los huicholes una expresión radical de las fuerzas ambivalentes que emanan del inframundo. $\mathrm{Al}$ igual que el peyote, el kieri se hace visible a través de múltiples formas y eventos en el mundo sensible. El examen del kieri proporciona una manera única y tal vez radical para explorar un ensamblaje de conocimientos, valores y prácticas que son marcadamente diferentes de los entrelazamientos con el espíritu del peyote que discutimos previamente.

La noción huichola de kieri porta una densa carga semántica que es difícil de captar desde un principio. Generalmente, en las distintas ocasiones que preguntamos a los huicholes sobre el kieri (en rituales, encuentros cotidianos, reuniones, comidas, etc.), los comentarios de las personas parecían inicialmente indicar que el kieri no existía. Con frecuencia, las referencias sobre esta entidad eran ignoradas o, a lo sumo, motivo de bromas que traslucían cierto nerviosismo. Sin embargo, en la quietud de la noche y en soledad, parecía emerger un discurso secreto en el que se entretejían fugaces referencias al kieri, a la muerte y a los gigantescos seres ancestrales (hewiixi).

En nuestras conversaciones con los habitantes de las localidades huicholas, especialmente cuando alguien se refería a temas relacionados con la muerte, a menudo la conversación se derivaba a la música mariachi (un género musical a través del cual los huicholes refieren que habla el kieri) y luego a otros tópicos relacionados con el kieri. De manera similar, cuando nuestros interlocutores decían algo sobre el kieri, aparecían con frecuencia temas conectados con la brujería, la locura y los sueños eróticos, así como narraciones sobre el fabuloso bestiario que habita en el fondo del Océano Pacífico y las granjas en Estados Unidos. Un fenómeno similar resulta factible de observar en las fuentes etnográficas que 
se refieren, dentro de un contexto más amplio, al kieri. Cuando etnógrafos como Benítez (2013), Benzi (1972), Furst y Myerhof (1966), Negrín (1985, 1986), Palafox Vargas (1985), Schaefer (1997), Yasumoto (1996), Zingg et al. (1998), entre otros, hacen referencia al kieri, tienden a mencionar una serie de otros tópicos, como la locura, los trastornos morales, la hechicería, la embriaguez, los accidentes violentos, la muerte, los eclipses, la conducta inusual de animales salvajes y los fenómenos repentinos como los torbellinos de viento. Un intrincado conjunto de actores humanos y no humanos se entrelazan de este modo en contextos de relaciones situadas -en la forma de juegos de lenguaje (Wittgenstein 1986)-, las cuales son reguladas por las condiciones pragmáticas en las que emergen.

La posición descentrada que caracteriza las experiencias del kieri en contraposición con el peyote -su eterno rival y emblema del orden cultural- sirve como un dispositivo heurístico para investigar (a modo de comparación) sobre la coexistencia de dos campos relacionales presentes tanto en la tradición oral como en las actuales prácticas rituales de los huicholes. De hecho, la figura del kieri condensa ${ }^{4}$ formas de relación que podrían ser vistas (desde la perspectiva del peyote) como antitéticas, de ahí su tendencia a socavar los órdenes sociales y cosmológicos. El kieri no es tan solo una compleja noción que puede ser movilizada para describir fenómenos muy diversos; es también una entidad con el poder de metamorfosearse y/o fragmentarse en una multitud de criaturas, artefactos y deidades (Aedo 2003).

Kieri es una fuerza delicada, secreta y peligrosa; es impredecible, furtiva e incontrolable. No es casualidad, entonces, que el kieri comúnmente se manifieste en el viento y otros fenómenos caprichosos. El kieri es a la vez una potencia letal y vital, que tiene la doble capacidad de generar bienes y virtudes, así como de engañar y perjudicar. Su carácter ominoso es frecuentemente enfatizado; los huicholes a menudo se refieren a esta fuerza como el "Diablo" o, más precisamente, como María (una habitante de Kwaxumayeme) lo describe, como el "culo del diablo." Resulta interesante observar que este nombre también hace referencia a un lugar al pie del cerro Picachos, donde músicos, comerciantes, artesanos y hechiceros realizan un culto nocturno. Su orgullo, ambición y lujuria conducen sus acciones y afirman su transgresión. El kieri maneja con maestría el arte de la transformación; sus formas de figuración revelan tanto sus gustos y ámbito relacional como su flexible ensamblaje de elementos y fenómenos. Según Chalío, un reputado chamán para los habitantes de Tateikie, el kieri gusta especialmente habitar los cuerpos de bellas mujeres extranjeras (uka teiwari) y de animales silvestres como zorras (kauxai) $)^{5}$ y lagartos, especialmente el imukwi (Heloderma horridum), una especie estrechamente relacionada con el mejor conocido Monstruo de Gila (Heloderma suspectum). Sin embargo, sus transformaciones no solo ocurren dentro del ámbito de lo sensible; la influencia del kieri puede empujar a los seres humanos a realizar actos desrazonables y a la pérdida del juicio moral. El desorden del comportamiento y el desconcierto de las cosas en el mundo implican una ruptura normativa, la cual provoca un estado alterado de conciencia, entendido como una forma de locura o tawetü, literalmente, la "embriaguez del espíritu".

Una sensación de fatalidad inquieta las experiencias de los huicholes con el kieri. El Occidente aparece como su región privilegiada, y la temporada de lluvias como el período de su apogeo. Pero el kieri es también una fuerza vital. De hecho, es un secreto a voces entre los huicholes que cada hombre y mujer tiene el potencial para ser iniciado en el conocimiento y dominio de las cosas a través de los poderes otorgados por el kieri. Sin embargo, el camino para convertirse en un chamán a través del kieri está lleno de peligros. Durante la noche, los fieles que buscan el favor del kieri, con precaución y a veces en secreto hacen ofrendas de velas, monedas, pequeñas botellas de la bebida ritual $t u c h i^{6}$, figuritas de ganado y flechas votivas en la base de la planta.

Desde una perspectiva sociológica, existe una distinción fundamental entre los campos relacionales característicos del peyote y del kieri. Mientras que el neófito del peyote tiene la posibilidad de obtener prestigio, su contraparte del kieri tiene la oportunidad de obtener poder económico e influencia a través de relaciones con instituciones estatales y dentro de la sociedad de mercado. Sin embargo, desde un punto de vista cosmopolítico, las relaciones con el kieri pueden conducir a vivir dentro de los límites del mundo (kiekari), dando lugar a experiencias de alteridad radical, tales como la locura (entendida como pérdida del sentido correcto de la vida), la riqueza monetaria y nuevas formas de subjetivación neoliberal en contextos multiculturales (Liffman 2012). Por el contrario, los entrelazamientos con el 
peyote toman forma a través de la experiencia de un mundo revelado, es decir, mediante el conocimiento de una verdad entregada como un regalo, "el don de ver" a través del peyote, el cual se expresa por el término nepühikurixie "conociendo dentro de los sueños del peyote". Según nos explicó Pedro de San Miguel Huaixtita, participar en la danza del peyote, Hikuri Neixa, implica:

agarrar el camino correcto, agarrando este punto de vista, esta energía, [porque] ... él [Peyote como Tamatsi Kauyumari] me da plumas, los cinco colores, diciendo esta es tu fuerza.

Las fuerzas del kieri y del peyote están situadas en enclaves de topologías relacionales (Haraway 2003; Jones 2009), que animan diferentes experiencias y formas de estar involucrado en acciones indivisibles de saber y hacer (Gibson 1979). Las rutas de conocimiento que se entrelazan con las fuerzas del kieri y del peyote producen relacionalidades en términos sociales (Bessire 2014; Povinelli 2002), cosmopolíticos (Descola 2013; Stengers 2005) y éticos (Keane 2016; Zigon 2014). Mientras que las prácticas rituales asociadas con el peyote promueven el ascetismo y las relaciones fraternales (como discute Rogers 2009), la ritualidad del kieri despliega una forma relacional completamente diferente, la cual enfatiza un modo de relación soberano/súbdito que se lleva a cabo dentro de un esquema de contrato fáustico, a la manera de la venta arquetípica del alma al diablo.

\section{El Entrelazamiento Performativo de las Imágenes y el Canto}

¿Qué tipo de imágenes están involucradas en las experiencias de conocimiento? ¿Cómo se aparecen dichas imágenes (Belting 2011) para devenir formas de conocimiento? Imágenes y objetos, tales como los teparite discos de piedra y las pinturas faciales $u x a$ de los peregrinos del peyote (hikuritamente) pueden definirse como "imágenes-acciones" (Bredekamp 2015), ya que por lo general, aparecen como formas "a punto de devenir" (Gamboni 2002:16), es decir, como valores expresivos capaces de orientar la imaginación y la acción.

Un ejemplo interesante en torno a las maneras en que las imágenes huicholas promulgan la agencia de entidades se observa en la Figura 1. Dicha imagen corresponde a la escultura de la deidad telúrica Tatei Uteanaka registrada por Lumholtz (1986). Representada como una figura femenina, esta escultura cubría originalmente un disco de piedra tepari dedicado a dicha entidad. $\mathrm{La}$ imagen presenta una serie de diseños distribuidos (espigas de maíz, vacas, serpientes y plumas de halcón) que no describen el cuerpo de Tatei Uteanaka en sí mismo, sino más bien la agencia que ejerce dicha entidad en un espacio y situación dada. El cuerpo femenino aparece sosteniendo un conjunto de mazorcas de maíz en sus brazos, gesto similar al que realizan muchas mujeres huicholas cuando portan sus ofrendas durante los rituales y peregrinaciones. Al mismo tiempo, el cuerpo de Tatei Uteanaka se presenta como un territorio, un entorno que está habitado por serpientes, campos de maíz, vacas e insectos que se reproducen en la época de lluvias. Dos bastones grabados en la escultura enfatizan la agencia de Tatei Uteanaka: uno debajo de su brazo derecho y otro en la espalda, los cuales en las narrativas huicholas constituyen los instrumentos utilizados por Tatei Uteanaka para hacer "crecer".

Los teparite que miden entre 80 y 100 centímetros de diámetro, por lo general cubren un agujero subterráneo (mawatirsawa, ver Zingg 1982, I:334) lleno de ofrendas, tales como velas, flechas y calabazas decoradas, entre otros objetos. De acuerdo con la noción de enraizamiento (nanayari) ${ }^{7}$, estos artefactos están ubicados estratégicamente en diferentes sitios, como los campos agrícolas (milpas), las zonas residenciales (ranchos), los edificios institucionales (escuelas y la sede del gobierno civil), y los templos ceremoniales (tukite).

Los teparite son a menudo grabados con espirales, círculos concéntricos, serpientes, venados, maíz y águilas, que ponen en relación algunas de las figuras fundamentales de la mitología y el pensamiento huichol. Como Lupe, una residente de Colorado de la Mora explicó, la iconografía teparite describe las "huellas de los antepasados" (Faba 2015), que se consideran como lo no completamente visible y presente. Estos elementos visuales constituyen, más bien, elementos operatoriamente latentes (DidiHuberman 2002; Warburg 2010).

Durante el ritual Hikuri Neixa de San Miguel Huaixtita, el canto del chamán (kawitu) permite a los participantes "ver" las imágenes de los teparite, las cuales revelan la presencia activa de una red 


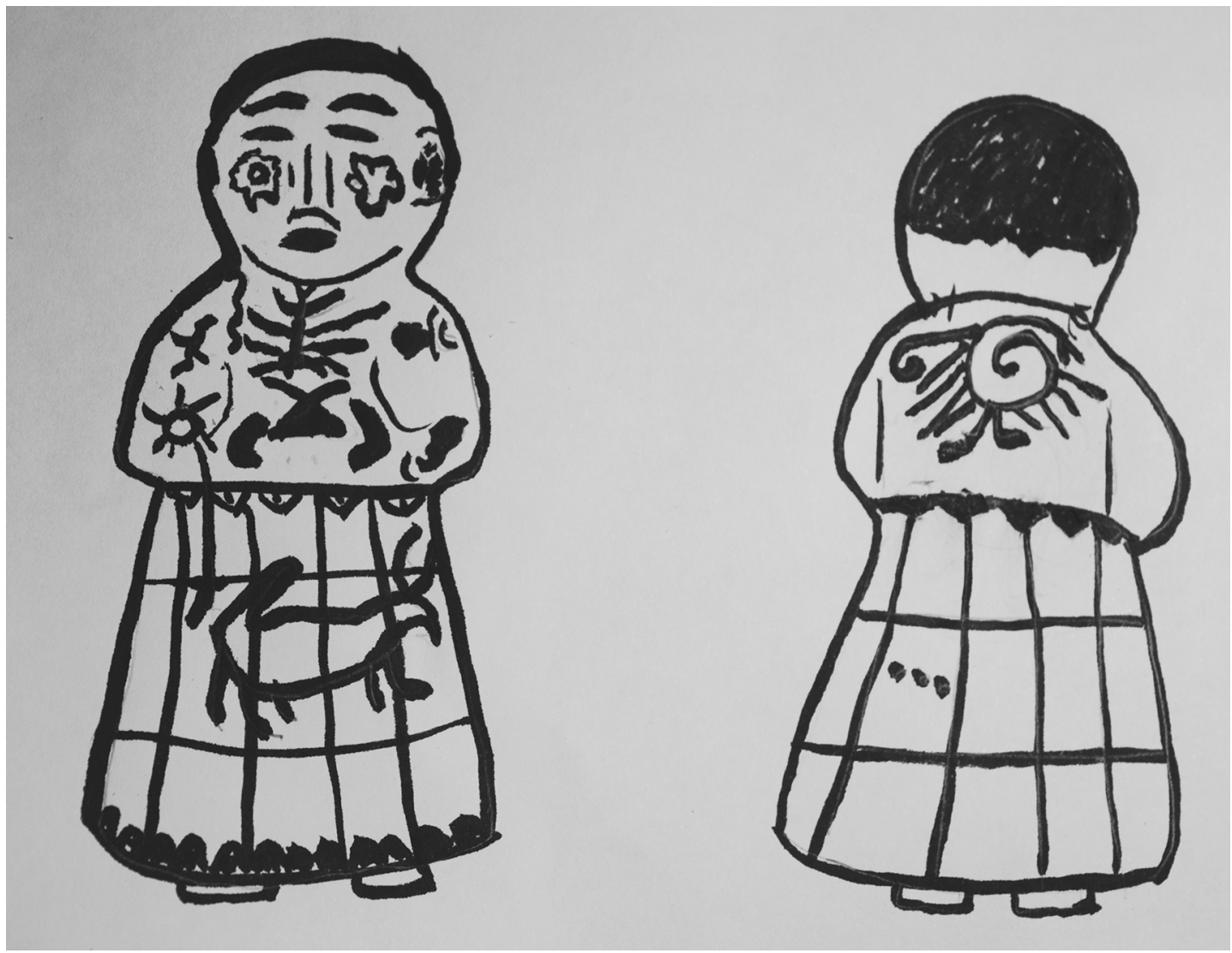

Figura 1. Escultura de Tatei Uteanaka. Diseño de los autores basado en Lumholtz (1986 [1902]).

Tatei Uteanaka sculpture. Design by the authors based on Lumholtz (1986 [1902]).

de entidades (Faba 2011). Como señala Neurath (2015a:71) en relación al contexto ritual vinculado a los teparite y al concepto de nierika $a^{8}$, "uno debe saber cómo ver" para tener una experiencia de conocimiento. En este sentido, el entrelazamiento de imágenes, objetos, palabras y movimientos hace énfasis en la presencia de las entidades como modos de acción. Como lo observa Lira (2014) en el marco de la vida ritual de la comunidad de Santa Catarina, los actos de conocimiento y transmisión de la memoria son posibles en un contexto performativo, en donde el entrelazamiento de las cosas, las intencionalidades y las subjetividades constituyen en sí mismos una experiencia. En este sentido, compartimos lo planteado por Keane, para quien "las formas de discurso ritual se ven afectadas por las acciones y suposiciones sobre el lenguaje y los seres que habitan en el mundo que les sirven de base" (Keane 1995:117).

A través del entrelazamiento mnemotécnico de la iconografía y las acciones rituales, los discos teparite revelan la historicidad y la temporalidad de los lugares. En este sentido, estos objetos pueden describirse como topos (Corsín Jiménez 2013; Henare et al. 2006; Wagner 1981), en donde el movimiento en espiral, motivo a menudo grabado en su superficie, es la manifestación de un indicio de la intra-acción (Barad 2007) que permite actualizar el vínculo con los antepasados, al coconstruir con los otros agentes del ritual el movimiento de emergencia y aparición desde el inframundo. A partir de la promulgación de este movimiento, se produce el entrelazamiento de los seres humanos y no humanos como entidades dotadas de intencionalidades y agencia. La articulación de la iconografía, la canción, el ritual, la topografía y las experiencias personales configuran y reconfiguran las formas huicholas de conocimiento y de saber, guiando las interpretaciones y compromisos con el mundo. En este marco, las imágenes expresan identidades a través de un contexto relacional que puede ser entendido como la manifestación de lo que describen como "sistemas de intensidades" 
que evidencian un "continuиm virtual de la vida" (Deleuze y Guattari 1980:25).

En una de las canciones (kawitu) del Hikuri Neixa que registramos en la comunidad Tateikie en 2001, Eugenio, el cantador principal se refirió a las entidades representadas en el disco de piedra como la aparición de la divinidad Tamatsi Kauyumari: "El venado azul está emergiendo, está llegando, está apareciendo. Es un pequeño ciervo, mira allí está emergiendo, míralo, está emergiendo el pequeño venado azul". En este canto, Eugenio hizo alusión a las imágenes del tepari, objeto que se muestra en la Figura 2, como indicios que anunciaban un acontecimiento por producirse durante el ritual. Las imágenes revelaron las huellas de Paritsika, en tanto indicios de la presencia de dicho antepasado en el aquí y el ahora de los humanos.

$\mathrm{Al}$ analizar la exégesis huichola de los objetos y su relación con la experiencia ritual, notamos que es principalmente a través de la atribución de intencionalidad a los elementos iconográficos, considerados como la manifestación de los antepasados, que se plantea como posible un compromiso colectivo y subjetivo con caminos de conocimiento. Refiriéndose a un cuadro de estambre que muestra Tamatsi Kauyumari en forma de un ciervo, rodeada por un círculo, con múltiples rayos, y cuatro figuras del peyote, Eligio Carrillo señaló que esta imagen contenía:

el poder de Kauyumari (el dios venado). Es como si él es un peyote. Pero al mismo tiempo se convierte en esto (un ciervo). Y él se transforma en un nierika. Él se transforma en la nada y en luz pura (Maclean 2012:62).

La interpretación de Eligio muestra cómo las imágenes son entidades multidimensionales que ponen en relación los niveles de experiencia.

En efecto, para muchos de los habitantes de las localidades huicholas con los cuales conversamos y compartimos las peregrinaciones y celebración de los rituales del ciclo anual, la recepción de los "mensajes" de las divinidades a través de imágenes adquiere dos implicaciones fenomenológicas: una experiencia subjetiva en donde uno se siente llamado a un camino de conocimiento (por la peregrinación y las prácticas de devoción), y una forma de compromiso colectivo (fundamentalmente en el marco de las familias extendidas) con una entidad particular, aspecto que se ve reflejado en el tipo de iconografía asociada a los discos teparite.

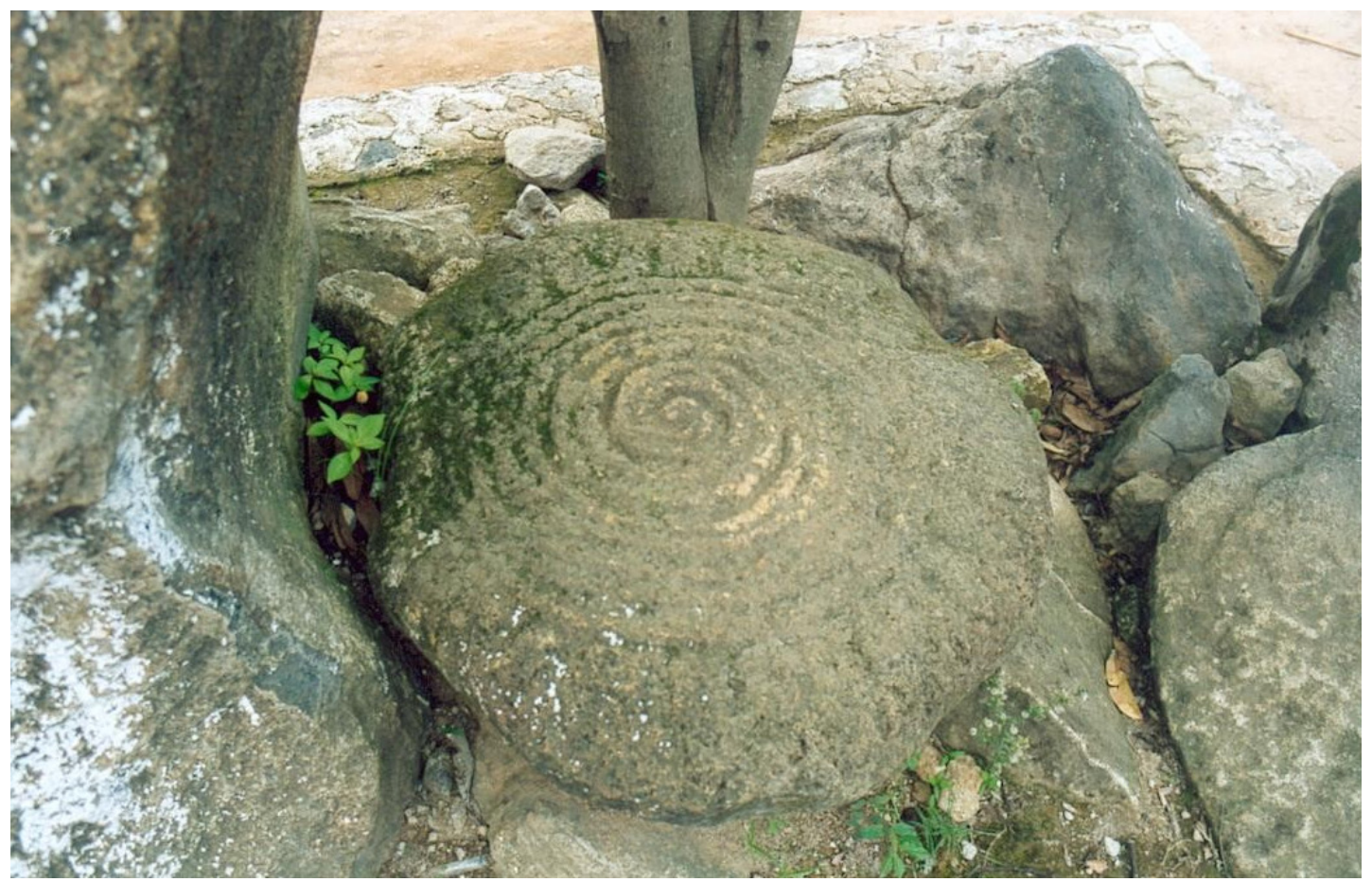

Figura 2. Tepari de Colonia Zitakua, Tepic, Nayarit. Fotografía de los autores.

Tepari from Colonia Zitakua, Tepic, Nayarit. Photo by the authors. 


\section{Los Descentramientos de Puntos de Vista}

Durante la segunda noche de desvelo correspondiente a la celebración del Hikuri Neixa ocurrida en 2003 en San Miguel Huaixtita, Ramón, uno de los asistentes a la festividad, explicó que a través de los efectos del peyote, imágenes y sonidos se manifiestan como las intencionalidades de diversas entidades no inmediatamente perceptibles y audibles en el paisaje. Según su testimonio, a través de las visiones del peyote, entidades como Tatéi $\mathrm{Na}$ ' ariwame aparecen como mensajes e intenciones de las divinidades.

Los sueños y la sinestesia psicodélicos son experiencias cruciales en la vida huichola. Constituyen una forma de relación con las imágenes que implica un constante cambio de puntos de vista entre el conocedor y lo conocido. Curiosamente Strathern ha observado un fenómeno similar en Papúa Nueva Guinea, donde: "verse a sí mismo en la vista del otro puede ser comprender ambos puntos de vista al mismo tiempo. La vista simultánea puede anticipar su diferenciación" (Strathern 2013:121). En contextos huicholes, Neurath (2015b) destaca de qué manera el "ver" constituye una actividad creativa, generativa y transformadora. Aprender a ver a través de la relación de uno con el peyote, por ejemplo, implica el reconocimiento mutuo de las entidades involucradas en una relación. Las imágenes tienen la capacidad de hacer y movilizar relaciones, donde un desplazamiento constante entre "lo que veo" y lo "que se ve" es posible.

La experiencia de Ascensión, un mara'akame de San Miguel Huaixtita constituye un ejemplo interesante de cómo las visiones involucran formas de intersubjetividad que conducen al conocimiento a través de operaciones de igualdad y diferenciación. Hace casi cuarenta y cinco años Ascención comenzó a soñar en repetidas ocasiones "en la naturaleza, como un águila, como una serpiente". Cuando visitó Wirikuta, por primera vez, soñó con "muchos animales como águilas y serpientes". "Caminé sobre miles de serpientes, no era la tierra, sino serpientes. De repente, muchos venados con cuernos amarillos aparecieron. Me miraron y preguntaron qué estaba haciendo en Wirikuta. Les expliqué que tomé la medicina (peyote) y que yo estaba visitando el lugar para llevar a cabo la costumbre con mi familia. Me dieron la bienvenida, y un gran venado azul, creo que fue Kauyumari, dijo: Te doy mi medicina, Te doy mi pluma, es mi fuerza, Te doy mi corazón, es mi luz. A partir de ese momento comenzaron a conocerme".

En este testimonio es interesante observar que las imágenes se manifiestan por primera vez como la fusión de puntos de vista, como Ascención estaba teniendo las visiones como si fuera 'de la naturaleza, águilas, serpientes’. Cuando viajó a Wirikuta, aparecieron entidades similares, pero la diferenciación de entidades se llevó a cabo como un proceso necesario para el reconocimiento y el conocimiento mutuo. Al ser su primera vez en Wirikuta, los venados, serpientes y el peyote se dirigieron a él como un extraño en el lugar. En este contexto, las imágenes funcionan como artefactos que viajan desde la fusión de puntos de vista para la diferenciación y el reconocimiento mutuo.

En este sentido, las pinturas faciales no son más que la manifestación de la agencia de entidades, que constituyen, además, una especie de registro iconográfico de identidad que captura la experiencia de Wirikuta (Faba 2003). Catarinillo, un residente de San Andrés Cohamiata, explicó que las pinturas faciales podrían definirse como 'credenciales' que cada peregrino debe exhibir cuando se mueve a través del paisaje ritual. Catarinillo intentó hacer hincapié en el hecho de que las pinturas faciales uxa operan efectivamente como una forma de identificación. Sin embargo, estas imágenes agencian la identidad de una manera muy diferente a como lo hace una credencial común. En los rostros de los peregrinos de Wirikuta se encuentran "todas las alucinaciones", refiere Neurath, "el paisaje mitológico se transforma en pintura facial autoengendrada" (Neurath 2010:210). Las pinturas faciales no expresan la identificación a través de la proyección de la apariencia física, sino que permiten el reconocimiento a través de la expresión visual de los sueños y visiones como formas de conocimiento y experiencia.

En una canción ritual (kawitu) registrada por Lemaistre (2012:315), realizada durante la peregrinación y la caza del peyote en Wirikuta, la reunión, el entrelazamiento, y el desplazamiento de las subjetividades y temporalidades se manifiestan por medio de una constelación de imágenes que describen la relación con el conocimiento a partir de estrategia de la huella y el mensaje, indicios de la presencia de el venado azul Paritsika:

hüriwari mutatsunaxüa Él saltó detrás de la colina 
hüriwari manekakeni

maxa yuawi manekakeni mana mana mukaruanaxü

uxaipari mekaneka'hini

Paritsika xemukamane

ana'ana'ari' xüarimü

xenierika 'himakamane

wawi'uxa himakamane

'ena'ena nete'ika'hüka

wawi'uxa nete'ika'hüka

tutu nierika nete' ika'hüka

Paritsika xemuyeyeika

netutsima mü xenierika

xe'uxari nepeka'üni'üni
Él se esconde detrás

de la colina

El venado azul

Allí sus pezuñas resonaron

dejando sus huellas

Eres tú, Paritsika

Ahora es realmente tu rostro

Es tu rostro

Es tu pintura, tu mensaje

Aquí estoy atento

Almensaje de lacanción

Al rostro de la flor del peyote

En tu caminar, Paritsika

Está en tu rostro, mis antepasados

Voy a recoger sus mensajes (Lemaistre 2012:315).

En este extracto Paritsika se presenta como una persona múltiple. El chamán se dirige a Paritsika utilizando la segunda persona del plural del pronombre xe lugar del pe singular. Durante el canto del tono de la voz del chamán se agudiza; en la medida que refiere la presencia de lo que parece ser la voz de Paritsika. Más tarde, en el entrelazamiento entre el canto, las acciones rituales y las imágenes de la tepari, lo que inicialmente constituía la presencia de Paritsika como persona múltiple, finalmente, se convierte en el despliegue de un campo relacional en el que las entidades parecen afectarse la una a la otra. Lo que en un inicio pareció ser la presencia de Paritsika finalmente se convirtió en la manifestación del peyote, a continuación, una flor y luego un grupo de ciervos llamado Paritsika maxa mate'awa, encargados de anunciar la llegada de la gran ciervo azul. A este respecto, es interesante observar que la constelación de imágenes desarrolladas por este canto construye un paisaje en el que diferentes puntos de vista se tejen para desarrollar la intuición y la incertidumbre.

\section{Conclusión}

Este artículo contribuyó a la identificación y el análisis de algunos aspectos cruciales de las experiencias que los huicholes conciben como formas de conocimiento. Focalizándonos en el entrelazamiento de acciones, imágenes, cantos y exégesis huicholas de experiencias individuales y colectivas, observamos cómo la anticipación, la indeterminación, la presencia de los índices visuales de la agencia y el devenir de los antepasados, así como el desplazamiento de las subjetividades, se despliegan como campos relacionales que desarrollan formas de conocimiento.

El artículo exploró cómo la incertidumbre emerge como un sentimiento que mantiene la tensión dramática de la experiencia ritual. Nos centramos en las formas a través de las cuales en contextos rituales el descubrimiento y encuentro con antepasados deificados afecta a sus participantes creando las condiciones para que las experiencias puedan convertirse en eventos memorables. A través del análisis de un momento del ritual de Tatei Neixa, analizamos la relación significativa entre la sensación de perder el camino de vuelta a casa y la manifestación de la anticipación de la experiencia como un tipo particular de conocimiento ritual que establece criterios para actuar en el mundo por venir. En este ritual la interrelación de imágenes, palabras y acciones demuestra que una "serie de prácticas puede constituir el marco que guía la inferencia e influye en la evocación" (Severi 2015:15).

La exploración del entrelazamiento de cosas, acciones y nociones mostró que los modos de subjetivación y agencia se despliegan a través de criterios arraigados en las formas de interacción. Esto nos llevó a considerar los campos relacionales del conocimiento en contextos huicholes como fenómenos de "intra-acción", es decir, como instancias que, en contraste con la habitual “interacción”, plantean la mutua constitución de los organismos entrelazados (Barad 2011). En este sentido, los artefactos huicholes y las imágenes aparecen como agentes claves en la formación de presencias y trayectorias de involucramiento con y en el mundo.

Partiendo de la exploración visual de los objetos e imágenes como los discos de piedra teparite y la escultura de Tatei Uteanaka, observamos de qué manera las imágenes se "aparecen" (Belting 2011) como índices de la agencia de las divinidades, orientando las formas de interpretación y las experiencias de conocimiento. Fue en este sentido que buscamos profundizar no solo en la manera que la materialidad de la significación se constituye en un factor para la interpretación, sino también en las 
formas en que "genera y transforma las modalidades de acción y la subjetividad" (Keane 2003:413). Bajo esta perspectiva, las pinturas faciales y los objetos, como los discos de piedra teparite podrían considerarse como imágenes expresivas (Dewey 1934). Es decir, como elementos que restauran y reproducen, a través de la expresión visual, diferentes experiencias de conocimiento. Sin embargo, a diferencia de la tradición del arte europeo clásico analizada por Dewey, en donde el "acto de imagen" (como define Bredekamp 2015) se concentra en producir la ilusión de movimiento, en el contexto huichol, los actos de imágenes se manifiestan como huellas, mensajes, pensamientos y efectos generados por la agencia de los antepasados.

A través de su entrelazamiento con acciones y palabras, las imágenes, en cuanto agentes fundamentales de las experiencias de conocimiento, no describen un mundo real, sino más bien reproducen la imaginación y la reflexividad. Como han argumentado Humphrey y Laidlaw (1994) y, más recientemente, Severi, los rituales:

No tienen que ser vistos como la ilustración estática de una verdad tradicional, sino más bien como el resultado de una serie de inferencias particulares, de actos individuales de interpretación que implican la duda, la incredulidad y la incertidumbre (Severi 2002:27).

Finalmente, a partir del estudio de los cantos rituales, la exégesis de las visiones producidas por el peyote, así como de las pinturas faciales, este artículo contribuyó a la comprensión del fenómeno de desplazamiento de puntos de vista como experiencia fundamental de conocimiento. Dicho descentramiento, que emerge del desarrollo de procesos reproductores de la imaginación, reveló de qué manera los fenómenos visuales pueden agenciar una pluralidad de dimensiones experienciales con el potencial de transformar el mundo.

Agradecimientos: Nuestra gratitud y reconocimiento va especialmente a nuestros amigos huicholes de larga data en Jalisco y Nayarit cuya generosidad y enseñanzas hicieron concebible este artículo. Las reflexiones desplegadas en esta investigación fueron animadas por varios colegas $\mathrm{y}$ amigos a quienes agradecemos profundamente, entre ellos, Patricia Carot, Arturo Gutiérrez, MarieAreti Hers, Francesca Merlan, Alan Rumsey y Carlo Severi. Nuestro reconocimiento va igualmente al Institute for Advanced Study, Princeton, por el apoyo entregado durante la escritura de este artículo en dicha institución. La investigación para este trabajo fue también posible por el Centro de Estudios Interculturales e Indígenas (CONICYT/FONDAP/15110006), la Vicerrectoría de Investigación y el Programa de Antropología de la Pontificia Universidad Católica de Chile, el Departamento de Antropología de la Universidad Alberto Hurtado y proyecto FONDECYT Iniciación $\left(\mathrm{N}^{\mathrm{o}}\right.$ 1160445). Finalmente, agradecemos a las editoras Vivien Standen y Eugenia Rosello, así como a los evaluadores anónimos de revista Chungara por sus perspicaces e instructivos comentarios.

\section{Referencias Citadas}

Aceves, R. 2005. Glosario de Cultura Huichola. Gobierno de Jalisco, Secretaría de Cultura, Guadalajara.

Aedo, A. 2003. La región más oscura del universo. Un paralelo entre el complejo mítico asociado al Kieri de los huicholes y al Toloatzin de los antiguos nahuas. En Flechadores de Estrellas, editado por J. Jáuregui y J. Neurath, pp. 221-249. INAH, Universidad de Guadalajara, México, D.F.

Aedo, A. 2008. ¿Por qué la ecología es también una ontología? Construcción de los conocimientos eco-cosmológicos de los Wixaritari. En Las Vías del Noroeste II, editado por M.-A. Hers, M.E. Olavarria, C. Bonfiglioli y A. Gutiérrez, pp. 347-374, UNAM, México, D.F.

Aedo, A. 2011. La Dimensión más Oscura de la Existencia. Indagaciones en Torno al Kieri de los Huicholes. Instituto de Investigaciones Antropológicas, UNAM, México, D.F.
Astuti, R. y M. Bloch 2015. The causal cognition of wrong doing: incest, intentionality, and morality. Frontiers in Psychology 6 (136):1-7.

Barad, K. 2007. Meeting the Universe Halfway. Quantum Physics and the Entanglement of Matter and Meaning. Duke University Press, Durham.

Barad, K. 2011. Erasers and erasures. Punch's unfortunate uncertain principle. Social Studies of Science 20:1-12.

Barth, F. 2002. An anthropology of knowledge. Sidney W. Mintz lecture for 2000. Current Anthropology 43:118.

Bateson, G. 1936. Naven. A Survey of the Problems Suggested by a Composite Picture of the Culture of a New Guinea Tribe Drawn from Three Points of View. Cambridge University Press, Cambridge. 
Bauman, R. 2012. Performance. En A Companion to Folklore, editado por R. Bendix y G. Hasan-Rokem, pp. 94-118, WileyBlackwell, Oxford.

Bauman, R. y Ch. Briggs 1990. Poetics and performance as critical perspectives on language and social life. Annual Review of Anthropology 19:59-88.

Belting, H. 2011. An Anthropology of Images: Picture, Medium, Body. Princeton University Press, Princeton.

Benítez, F. 2013 [1968]. En la Tierra Mágica del Peyote. Ediciones Era, México, D.F.

Benzi, M. 1972. Les Derniers Adorateurs du Peyotl. Gallimard, Paris.

Berliner D. y R. Sarró 2008. On learning religion: An introduction. En Learning Religion: Anthropological Approaches, editado por D. Berliner y R. Sarró, pp. 1-19, Berghan Books, New York-Oxford.

Bessire, L. 2014. Behold the Black Caiman: A Chronicle of Ayoreo Life. University of Chicago Press, Chicago.

Bloch, M. 1998. How we think they Think. Anthropological Approaches to Cognition, Memory and Literacy. Westview Press, Boulder.

Bloch, M. 2012. Anthropology and the Cognitive Challenge. New Departures in Anthropology. Cambridge University Press, Cambridge.

Boyer, P. 1994. The Naturalness of Religious Ideas. A Cognitive Theory of Religion. University of California Press, Berkeley, Los Angeles.

Bredekamp, H. 2015. Théorie de l'Acte d'Image. Éditions La Découverte, Paris.

Cavell, S. 1999 [1979]. The Claim of Reason: Wittgenstein, Skepticism, Morality and Tragedy. Oxford University Press, Oxford.

Corsín Jiménez, A. 2013. An Anthropological Trompe L'oeil for a Common World. An Essay on the Economy of Knowledge. Berghan Books, New York-Oxford.

D'Andrade, R. 1995. The Development of Cognitive Anthropology. Cambridge University Press, Cambridge.

Deleuze, G. 1997 [1986]. Foldings, or the inside of thought (Subjectification). En Foucault. University of Minnesota Press, Minneapolis.

Deleuze, G. y F. Guattari 1980. Mille plateaux: Capitalisme et Schizophrénie, 2. Minuit, Paris.

Descola, P. 2010. La Fabrique des Images. Visions du Monde et Formes de la Représentation. Somogy-Musée du quai Branly, París.

Descola, P. 2013. Beyond Nature and Culture. The University of Chicago Press, Chicago.

Dewey, J. 1916. Essays in Experimental Logic. Dover, New York.

Dewey, J. 1934. Art as Experience. Putnam, New York.

Didi-Huberman, G. 2002. L'image Survivante. Histoire de l'Art et Temps des Fantômes selon Aby Warburg. Les Éditions de Minuit, Paris.

Faba, P. 2003. Los rostros de nuestros antepasados. Las pinturas faciales de los Jicareros (Xukurikate) huicholes de Tateikita. Anales del Instituto de Investigaciones Estéticas 25 (82):73-92.
Faba, P. 2011. Imágenes de una Memoria. Pensar el Pasado entre los Huicholes Wixaritari del Occidente de México. IIEIIA, UNAM, México, D.F.

Faba, P. 2015. Arte y presencia entre los Huicholes (Wixaritari) del Occidente de México. Revista de Teoría del Arte 1 (26):43-54.

Fassin, D. (ed.) 2012. A Companion to Moral Anthropology. Wiley-Blackwell, Malden.

Faubion, J. 2011. An Anthropology of Ethics. Cambridge University Press, Cambridge.

Foucault, M. 1988 [1984]. The Care of Self. Volume 3 of the History of Sexuality. Vintage Books Editions, New York.

Foucault, M. 1990 [1984]. The Use of Pleasure. Volume 2 of the History of Sexuality. Vintage Books Editions, New York.

Foucault, M. 2007. Security, Territory, Population: Lectures at the Collège de France, 1977-78. Palgrave, New York.

Foucault, M. 2012. Du Gouvernement des Vivants. Cours au Collège de France 1979-1980. Editado por M. Senellart, EHESS-Seuil-Gallimard, Paris.

Furst, P. 1972. To find our life: Peyote among the Huichol indians of Mexico. En Flesh of the Gods: The Ritual Use of Hallucinogens, editado por P. Furst, pp. 184-236. Praeger, New York.

Furst P. y B. Myerhof 1966. Myht as history. The Jimsonweed cycle of the Huichols of Mexico. Antropológica 17:3-39.

Gamboni, D. 2002. Potential Images. Ambiguity and Indeterminacy in Modern Art. Reaktion Books, London.

Gibson, J. 1979. The Ecological Approach to Visual Perception. Houghton Mifflin, Boston.

Goffman, E. 1981. Forms of Talk. University of Pennsylvania Press, Philadelphia.

Gutiérrez del Ángel, A. 2002. La Peregrinación a Wirikuta: el Gran Rito de Paso de los Huicholes. Instituto Nacional de Antropología e Historia, México, D.F.

Haraway, D. 2003. The Companion Species Manifesto: Dogs, People and Significant Otherness. Prickly Paradigm Press, Chicago.

Henare, A., M. Holbraad y S. Wastell 2006. Thinking through Things. Theorising Artefacts Ethnographically. Routledge, London and New York.

Højbjerg, Ch.K. 2002. Religious reflexivity. Essays on attitude to religious ideas and practice. Social Anthropology 10:1-10.

Houseman, M. y C. Severi 1998. Naven or the Other Self. A Relational Approach to Ritual Action. Brill, Leiden, Boston, Köln.

Humphrey, C. y J. Laidlaw 1994. The Archetypal Actions of Ritual: An Essay on Ritual Action as Action Illustrated by the Jain Rite of Worship. Oxford University Press, Oxford.

Jones, M. 2009. Phase space: geography, relational thinking, and beyond. Progress in Human Geography 33 (4):487-506.

Keane, W. 1995. The spoken house. Text, act and object in Eastern Indonesia. American Ethnologist 22 (1):102-124.

Keane, W. 2003. Semiotics and the social analysis of material things. Language and Communication 23:409-425.

Keane, W. 2016. Ethical Life: Its Natural and Social Histories. Princeton University Press, Princeton. 
Knab, T. 1977. Notes concerning use of Solandra among the Huichol. Economic Botany 31:80-86.

Lemaistre, D. 2003. Le Chamane et son Chant. Relations Ethnographiques d'une Expérience Parmi les Huicholes du Mexique. L'Harmattan, Paris.

Lemaistre, D. 2012. El hilo textil y el hilo sonoro. Dos mundos que se entrelazan. En Hilando al Norte. Nudos, Redes, Vestidos, Textiles, editado por A. Gutiérrez del Ángel, pp. 303-320. Colegio de San Luis, El Colegio de la Frontera Norte, San Luis Potosí.

Lemke, T. 2014. New Materialisms: Foucault and the "Government of Things." Theory, Culture \& Society 32 (4):3-25.

Liffman, P. 2005. Raíces y fuegos: estructuras cosmológicas y procesos históricos en la territorialidad huichol. Relaciones 26 (101):51-79.

Liffman, P. 2012. La Territorialidad Wixarika y el Espacio Nacional. Reivindicación Indígena en el Occidente de México. El Colegio de Michoacán, CIESAS, Zamora.

Lira, R. 2014. L'Alliance entre la Mere Maïs et le Frère Ainé Cerf: Action, Chant et Image dans un Rituel Wixárika (Huichol) du Mexique. Tesis de Doctorado en Antropología Social y Etnología. École des Hautes Études en Sciences Sociales, París.

Lumholtz, C. 1986 [1902]. El Arte Simbólico y Decorativo de los Huicholes. Instituto Nacional Indigenista, México, D.F

MacCauley, R. y E.T. Lawson 2002. Bringing Ritual to Mind. Psychological Foundations of Cultural Forms. Cambridge University Press, Cambridge.

MacLean, H. 2012. The Shaman's Mirror. Visionary Art of the Huichol. University of Texas Press, Austin.

McIntosh, J.B. y J. Grimes 1954. Vocabulario Huichol-Castellano Castellano-Huichol. Instituto Lingüístico de Verano, México, D.F.

Morris, R. C. 2000. In the Place of Origins, Modernity and Its Mediums in Northern Thailand. Duke University Press, Durham.

Myerhoff, B. 1974. Peyote Hunt. The Sacred Journey of the Huichol Indians. Cornell University Press, Ithaca y Londres.

Negrín, J. 1985. Acercamiento Histórico y Subjetivo al Huichol. EDUG, Universidad de Guadalajara, Guadalajara.

Negrín, J. 1986. Nierica: Espejo entre Dos Mundos. Arte Contemporáneo Huichol. Museo de Arte Moderno, México, D.F.

Neurath, J. 2002. Las Fiestas de la Casa Grande: Ritual Agrícola, Iniciación y Cosmovisión en una Comunidad Wixarika (T+apurie/Santa Catarina Cuexcomatitán). Instituto Nacional de Antropología e Historia, México, D.F.

Neurath, J. 2010 Simultanéité de visions: le nierika dans les rituels et l'art des Huichols. En La Fabrique des Images. Visions du Monde et Formes de la Representation, editado por P. Descola, pp. 203-214, Musée du Quai Branly, París.

Neurath, J. 2015a. Complex relations and modifications of visibility: Ceremonial pits and sacrificial stones among the Huichols. En Montrer Occulter. Cahiers d'Anthropologie Sociale 11, editado por P. Pitrou y G. Ollivier, pp. 70-83, Éditions de l'Herne, París.

Neurath, J. 2015b. Shifting ontologies in Huichol ritual and art. Anthropology and Humanism 40 (1):58-71.
Palafox Vargas, M. 1985. Violencia, Droga y Sexo entre los Huicholes. Instituto Nacional de Antropología e Historia, México, D.F.

Peirce, Ch.S. 1931-58. Collected Papers of Charles Sanders Peirce. 8 vols, editado por Ch. Hartshorne, P. Weiss y A.W. Burks. Belknap Press of Harvard University Press, Cambridge.

Pietz, W. 1985. The problem of the fetish, Part 1. Res 9:5-17.

Povinelli, E. 2001. Radical worlds: The anthropology of incommensurability and inconceivability. Annual Review of Anthropology 30:319-334.

Povinelli, E. 2002. The Cunning of Recognition. Indigenous Alterities and the Making of Australian Multiculturalism. Duke University Press, Durham.

Rogers, D. 2009. The Old Faith and the Russian Land: A Historical Ethnography of Ethics in the Urals. Cornell University Press, Ithaca, New York.

Schaefer, S. 1997. The Crossing of Souls: Peyote Perceptions and Meanings Among the Huichol Indians. En People of the Peyote. Huichol Indian History, Religion and Survival, editado por S. Schaefer y P. Furst, pp. 138-168. University of New Mexico Press, Alburquerque.

Schaefer, S. 2005. Plants and healing on the Wixarika (Huichol) Peyote pilgrimage. En Pilgrimage and Healing, editado por J. Dubuish y M. Winkelman, pp. 179-201, University of Arizona Press, Tucson.

Schaefer, S. y P. Furst 1996. People of the Peyote. Huichol Indian History, Religion and Survival. University of New Mexico Press, Alburquerque.

Severi, C. 2002. Memory, reflexivity and belief. Reflections on the ritual use of language. Social Anthropology 10:23-40.

Severi, C. 2014. Transmutating Beings. A Proposal for an Anthropology of Thought. Hau: Journal of Ethnographic Theory 4 (2):41-71.

Severi, C. 2015. The Chimera Principle. An Anthropology of Memory and Imagination. Chicago University Press, Hau Books, Chicago.

Silverstein, M. 1993. Harold Pinter and the Language of Cultural Power. Lewisburg, Bucknel University Press, Associated University Presses, Londres y Toronto.

Sperber, D. 1996. Explaining Culture: A Naturalistic Approach. Blackwell, Oxford.

Stengers, I. 2005. The Cosmopolitical Proposal. En Making Things Public: Atmospheres of Democracy, editado por B. Latour y P. Weibel, pp. 994-1003, MIT Press, Cambridge.

Strathern, M. 2013. Learning to See in Melanesia. Lectures Given in the Department of Social Anthropology, Cambridge University 1993-2008. HAU Master Class Series 2, Manchester.

Taussig, M. 1993. Maleficium: State fetishism. En Fetishism as Cultural Discourse, editado por E. Apter y W. Pietz, pp. 217-247, Cornell University Press, Ithaca.

Urban, G. 2001. Metaculture. How Culture Moves Through the World. University of Minnesota Press, Minneapolis.

Wagner, R. 1981 [1975]. The Invention of Culture. University of Chicago Press, Chicago y London.

Warburg, A. 2010. Atlas Mnemosyne. Akal, Madrid. 
Whitehouse, H. 2012. Ritual, cognition, and evolution. En Grounding the Social Sciences in the Cognitive Sciences, editado por R. Sun, pp. 265-284. MIT Press, Cambridge, Massachusetts.

Wittgenstein, L. 1986 [1958]. Philosophical Investigations. Basil Blackwell, Oxford.

Yasumoto, M. 1996. The psychotorpic Kieri in Huichol Culture. En People of the Peyote. En Huichol Indian History, Religion and Survival, editado por S. Schaefer y P. Furst, pp. 236-263, University of New Mexico Press, Alburquerque.
Zigon, J. 2014. Attunement and fidelity: Two ontological conditions for morally being-in-the-world. Ethos 42 (1):16-30.

Zigon, J. 2015. What is a situation? An assemblic ethnography of the drug war. Cultural Anthropology 30 (3):501-524.

Zingg, R. 1982. Los Huicholes. Una Tribu de Artistas, I. INI, México, D.F.

Zingg, R., J.C. Fikes, P.C. Weigand y A. García 1998. La Mitología de los Huicholes. El Colegio de Michoacán, Zamora.

\section{Notas}

1 Los autores hicieron juntos trabajo de campo extensivo, constituido por visitas intermitentes entre 1998 y 2003. Durante estas visitas participaron de la peregrinación a Wirikuta y de las ceremonias religiosas neixa, así como de los rituales del calendario católico. Los datos del trabajo de campo fueron registrados en diarios de campo y grabadora de voz.

2 La vida heroica de Tamatsi Kauyumari (ancestro deificado y una de las manifestaciones del peyote), enseña el alto valor del autosacrificio. La práctica de la reciprocidad es un modo relacional emblemático en los rituales y mitos del peyote, constituyendo el ascetismo un comportamiento paradigmático de los peregrinos de Wirikuta.

3 La peregrinación al desierto Wirikuta también es vista por los huicholes como una forma de cacería del peyote.

4 En cuanto a la idea de condensación, nos inspiramos en el análisis llevado a cabo por Houseman y Severi (1998) en la ceremonia del naven de los Iatmul en Papúa Nueva Guinea, descrita previamente por Bateson (1936).

5 Para la transcripción del vocabulario relacionado con la fauna huichola nos basamos en Aceves (2005:133-140).

6 El tuchi es un destilado artesanal de agave que realizan los huicholes principalmente durante la temporada de lluvias. En dicho momento muchas familias se retiran a ranchos cercanos a las áreas de pastoreo de sus reses de ganado para aprovechar la leche y hacer queso.

7 Liffman (2005), ha señalado que la noción huichola de enraizamiento nanayari (de nana, enredadera o planta trepadora) se asocia íntimamente con la categoría de kiekari (mundo), término que hace hincapié en los lazos y las trayectorias que articulan un espacio de duración y un territorio histórico, con frecuencia señalado por los discos teparite.

8 La etimología de la palabra nierika viene del verbo nieriya "ver" (McIntosh y Grimes 1954). 